\title{
Proposal of surface electromyography signal acquisition protocols for masseter and temporalis muscles
}

\author{
Ana Sabaneeff ${ }^{1}$, Luciana Duarte Caldas ${ }^{1}$, Marco Antonio Cavalcanti Garcia ${ }^{2}$, \\ Matilde da Cunha Gonçalves Nojima ${ }^{1 *}$ \\ ${ }^{I}$ Department of Orthodontics, School of Dentistry, Federal University of Rio de Janeiro, Rio de Janeiro, RJ, Brazil \\ ${ }^{2}$ Department of Biosciences and Physical Activities, School of Physical Education and Sports, Federal University of Rio de Janeiro, \\ Rio de Janeiro, RJ, Brazil
}

\begin{abstract}
Introduction: The aim of this study was to propose a method of electrodes positioning on the superficial masseter and anterior temporalis muscles for surface electromyographic (sEMG) recordings in order to overcome some known methodological constraints. Methods: Fifteen volunteers with normal occlusion participated in two experimental sessions within a 7 day-period. Surface electrodes were placed on two different locations that were based on palpable and individual anatomical references. Surface EMG signals (2000 Hz per channel; A/D: 16 bits; gain: $2000 \mathrm{X}$; band-pass filter: 20-500 Hz) were recorded under three conditions: mandibular rest position, 30\% and $100 \%$ of maximum voluntary bite force. Three measurements of maximal bite force were taken by using a force transducer positioned over the lower right first molar region and the highest record was taken into account. The root mean square value was considered for analysis. Intraclass correlation coefficients (ICCs), paired t test, and the Bland-Altman method comprised the statistical analyses. The level of significance was set at 0.05 . Results: ICC records for right and left masseter and anterior temporalis muscles at $\mathrm{T}_{0}$ (first sEMG record) and $\mathrm{T}_{7}$ (second $\mathrm{sEMG}$ record) intervals were significantly different $(\mathrm{p}<0.05)$. The results showed satisfactory to excellent reproducibility of RMS values at rest, MVBF and 30\% MVBF, as well as for MVBF in kgf. Conclusion: The results showed reliable reproducibility for the sEMG signal recording in masseter and anterior temporalis muscles from the protocols presented and under the three conditions investigated.
\end{abstract}

Keywords Electromyography, Masseter muscle, Temporalis muscle, Surface electrodes, Face, Oral physiology.

\section{Introduction}

Surface electromyography (sEMG) has increasingly been used as an adjunct method to evaluate the biomechanics of mastication (Gonzalez et al., 2011). However, different variables have been identified as critical to the quality of sEMG signal, and subsequently to the information it supplies. Age, gender, facial anatomy and fat tissue distribution are ordinary examples of such intervening variables (Castroflorio et al., 2008; Klasser and Okeson,

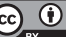

This is an Open Access article distributed under the terms of the Creative Commons Attribution License, which permits unrestricted use, distribution, and reproduction in any medium, provided the original work is properly cited.

How to cite this article: Sabaneeff A, Caldas LD, Garcia MAC, Nojima MCG. Proposal of surface electromyography signal acquisition protocols for masseter and temporalis muscles. Res Biomed Eng. 2017; 33(4):324-330. DOI: 10.1590/2446-4740.03617.

*Corresponding author: Programa de Pós-graduação em Odontologia - Ortodontia, Departamento de Ortodontia, Faculdade de Odontologia, Universidade Federal do Rio de Janeiro, Av. Professor Rodolpho Paulo Rocco, 325, Cidade Universitária, Ilha do Fundão, CEP 21941-617, Rio de Janeiro, RJ, Brazil. E-mail: matildenojima@uol.com.br Received: 05 July 2017 / Accepted: 23 November 2017
2006; Suvinen and Kemppainen, 2007; Suvinen et al., 2009). Moreover, there seems to be no consensus with regard to the sEMG protocols and parameters established for the recording of this signal from masticatory muscles although Castroflorio et al. $(2005 ; 2006)$ highlight the importance of some methodological issues that must be taken in account whenever we intend to record the sEMG activity from some facial muscles. For instance, the electrodes placement and the distance between them in bipolar configuration can compromise the quality of monitoring in a same patient within sessions, as the amplitude and spectral contents of this signal may dramatically vary depending on the protocol adopted (Castroflorio et al., 2008; Garcia and Vieira, 2011; Merletti and Parker, 2004; Suvinen and Kemppainen, 2007).

Particularly in sEMG, the reproducibility of electrodes positioning is critical in longitudinal studies (Merletti and Parker, 2004) mainly due the lack of ensuring the monitoring of a particular muscular location and thus leading to a misinterpretation of the sEMG data whenever consecutive measurements are taken from the same individual (Donaldson and Donaldson, 1990) as previously mentioned. Therefore, the present recommendations 
may help clinicians to better examine and evaluate the muscle activity before and after treatment from a particular location, since the spatial distribution of motor unit action potentials are not uniform through the whole extension of a muscle (Garcia and Vieira, 2011; Merletti and Parker, 2004). Such a recommendation may ensure the sEMG signal record from the same muscle volume along consecutive examinations and so a more robust clinical interpretation can be achieved. The International Society of Electrophysiology and Kinesiology (ISEK) has suggested the use of a set of norms in the process of acquiring and analyzing this signal, all compiled into a Project named SENIAM ("Surface EMG for Non Invasive Assessment of Muscles") (Hermens et al., 2000). SENIAM raises awareness of the importance of following its protocols for electrodes placement, which were compiled from anatomical and functional features of different muscles even though it does not take in account facial or masticatory muscles. In addition, due to the small number of studies that present methodological proposals for electrode placement on specific muscles associated with mastication, there seems to be a lack of consistency among them (Pedroni et al., 2004).

Therefore, according to the aforementioned, the aim of this study was to develop protocols for surface electrodes positioning on two facial muscles: the superficial masseter and anterior temporalis. It is also worth highlighting that they were conceived based on easily palpable and specific anatomical landmarks to guide clinicians in their routine and guarantee reproducibility between multiple sEMG recordings.

\section{Methods}

Fifteen volunteers of both genders ( 7 men and 8 women, age: $24.4 \pm 5$ years) were recruited for this study. They were all clinically evaluated and presented normal occlusal characteristics (adequate dental intercuspation, correct canine relationship, overjet ranging from 2 to $3 \mathrm{~mm}$, overbite between $10 \%$ and $50 \%$, presence of anterior and lateral guidance, as well as lip competence) and lack of clinical signs of temporomandibular joint dysfunction. This project was approved by the Ethical Committee on Research of the Public Health Institute, Federal University of Rio de Janeiro in Brazil (number $108 / 2009$, process number 35/2009). All volunteers gave written informed consent prior being advised about the procedures adopted in this study.

A 5-channels EMG system was used, of which 4 were used for sEMG signal recording and 1 was connected to a force transducer (EMG System of Brazil, São José dos Campos, SP, Brazil - sampling frequency of $2000 \mathrm{~Hz}$ per channel; A/D: 16 bits; gain: $2000 \mathrm{X}$; band-pass filter:
20-500 Hz; common mode rejection rate (CMRR): $>100 \mathrm{~dB}$ ). Active bipolar surface electrodes were used.

During sEMG signals recording, volunteers remained seated in an upright position on a chair without a headrest, natural head position, and Frankfort horizontal plane parallel to the ground; their feet were on the floor and hands rested on the thighs, according to the methodology proposed by previous studies (Castroflorio et al., 2005; 2006; Tosato and Caria, 2007).

The sEMG signals were recorded from superficial masseter (SM) and anterior temporalis (AT) muscles at mandibular rest position, maximum voluntary bite force (MVBF - kgf) and 30\% of MVBF. A force transducer (Alfa Instrumentos Eletrônicos, Ltda; nominal capacity: $200 \mathrm{kgf}$; sensitivity: $2 \mathrm{mV} / \mathrm{V}$ ), specifically designed for recording mastication efforts, was positioned over the lower right first molar in tests of bite force. At rest position, the volunteers were asked to avoid movements and occlusal tooth contacts, and to keep the lips relaxed. The acquisition of sEMG signal lasted 5 seconds in this last position. MVBF corresponded to the highest value in kgf after three recordings, of 3 seconds each, when the volunteers were asked to perform a maximal bite effort. A target force set at $30 \%$ of the MVBF was calculated and used in a third moment of sEMG signal acquisition. A target line, corresponding to $30 \%$ of MVBF, was continuously presented to the volunteers as a way of providing a visual feedback to guide the maintenance of the level of muscle contraction. All sEMG signal recordings were performed by the same operator at two different instants of time ( $\mathrm{T}_{0}$, first sample; $\mathrm{T}_{7}$, second sample), within a seven day interval, so that operator would not be able to memorize electrodes positioning.

The locations for electrodes positioning were previously shaved and cleaned with neutral soap in order to maximize the signal/noise ratio ( $\mathrm{S} / \mathrm{N}$ ratio), as recommended by SENIAM (Hermens et al., 2000). Male volunteers were instructed to have their beard shaved prior to the sEMG signal recordings. Surface self-adhesive electrodes (hypoallergenic acrylic adhesive, 3M Brazil LTDA, Ag-AgCl, $1 \mathrm{~cm}$ diameter, model 2223BR, Sumaré, SP, Brazil) were used to collect the sEMG signals.

The reference electrode was positioned over C7 vertebra (Garcia-Morales et al., 2003), identified as the most prominent part of the cervical spine not to translate forward when the head is flexed (Hackney et al., 1993). A bipolar electrodes configuration was set up over the muscles of interest (AT and SM) by using an inter-electrodes distance (IED) of $15 \mathrm{~mm}$.

In order to locate the areas of interest over each muscle, three straight lines were determined from easily palpable anatomical landmarks. On the anterior portion of the AT muscle, two lines were identified, one vertical 
and another horizontal $\left(\mathrm{TL}_{\mathrm{V}}\right.$ and $\mathrm{TL}_{\mathrm{H}}$, respectively). $\mathrm{TL}_{\mathrm{V}}$ line corresponded to the bony prominence formed by the zygomatic process of the frontal bone and the posterior limit of the frontal process of the zygomatic bone; while $\mathrm{TL}_{\mathrm{H}}$ line corresponds to the upper border of the zygomatic arch (Figure 1). The electrodes were placed according to the fibers direction of AT muscle, just above the upper edge of the zygomatic arch, posterior to line $\mathrm{TL}_{\mathrm{v}}$ and anterior to the scalp (Figure 2).

In order to place the electrodes over the SM muscle, Gonion (Go) - located at the angle of the mandible - and the body of zygomatic bone were both identified by palpation. The SM muscle line (ML) was drawn from these reference landmarks, joining Go, spotted on the soft tissue, to the mid-point between the lower posterior border of the zygomatic bone and the zygomatic arch (Figure 1), both also identified by palpation. ML was adjusted to fibers direction of SM muscle (Chan et al., 2008), which is congruent with its origin and insertion. The SM muscle is covered by a tendinous layer that extends from the zygomatic bone to $1 / 3$ to $1 / 2$ of its length (Suvinen et al., 2009). It is not recommended to place electrodes over tendinous areas, so a reference point was identified at $40 \%$ of the length of ML from Go. The electrodes were placed along this reference line, with their location of placement on the mark corresponding to $40 \%$ of ML (Figure 2).

After setting out all the reference points and lines, the volunteers were asked to clench the teeth so as to confirm whether the suggested anatomical landmarks needed any adjustments. The surface electrodes should be placed along muscle fibers, over the most prominent region at the moment of muscle contraction. While palpating the muscle during contraction, it was possible to verify electrodes positioning to perform any need of correction. All corrections in electrode positions and their respective amounts were duly noted.

In order to compare different conditions, the root mean square (RMS) values of the SM and AT (right and left) myoelectric activities were calculated at rest, MVBF and 30\% MVBF for both moments (T0 and T7) from the sEMG data collection established in this study (Equation 1).

$$
R M S=\sqrt{\frac{1}{N} \sum_{n=1}^{N} E M G[n]^{2}}
$$

Where $N$ represents the number of samples to be averaged within intervals established for analysis, as shown below.

An epoch of 0.5 second duration from a 3 -second of sEMG raw signal, corresponding to the moment of peak force, was used for MVBF analysis; a total recording time ( 5 seconds) was used for analyzing rest position; and an epoch of 5 -second duration from the moment

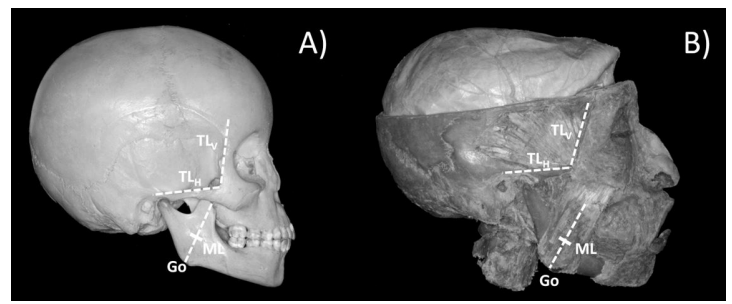

Figure 1. (A) The lateral view of skull shows the reference lines used in this study: $\mathrm{TL}_{\mathrm{r}}, \mathrm{TL}_{\mathrm{H}}$ and ML. The small thick line represents an intersection at $40 \%$ the length of ML from Go landmarck; (B) Lateral view of deep facial planes, evidencing the AT and SM muscles and their relationship with anatomical landmarks and reference lines adopted.

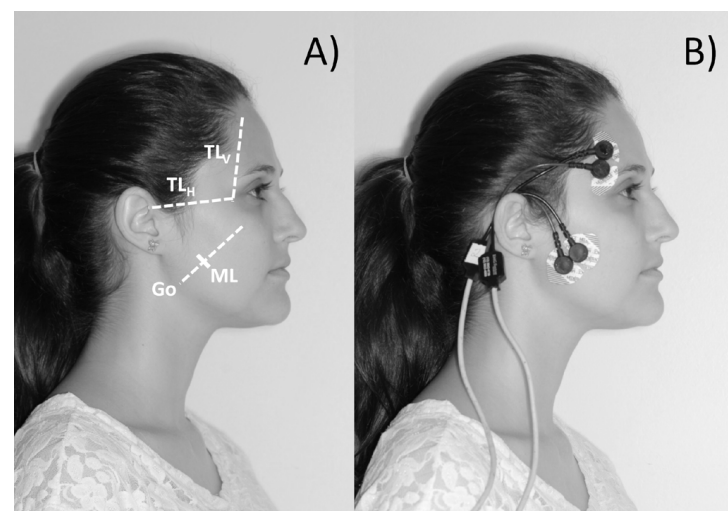

Figure 2. (A) Reference lines drawn on the face of a volunteer; (B) electrodes positioned over the AT and SM muscles.

the force reached the target level and remained constant was used for $30 \% \mathrm{MVBF}$ signal analysis.

\section{Statistical analyses}

The agreement of RMS values at rest and 30\% MVBF was assessed by means the Bland-Altman method for each muscle separately, with upper and lower limits of agreement set at $95 \%$. Therefore, the paired t-test was used to verify differences between Intraclass correlation coefficients (ICCs) at $\mathrm{T}_{0}$ and $\mathrm{T}_{7}$ but also for each individual muscle. The ICCs allowed us to test RMS values at rest, MVBF and 30\% MVBF.

\section{Results}

The Bland-Altman plots depict, with the exception of a few outliers, an even distribution of points within the $95 \%$ limits of agreement (Figure 3 and 4). The displacements of mean differences from zero were not statistically significant ( $p>0.05$ ). At rest, RMS values from $\mathrm{SM}$ muscle were $5 \pm 2.5 \mu \mathrm{V}$, while AT values ranged from 3.5 to $16 \mu \mathrm{V}$ (Figure 3).

According to the paired t-test, the ICCs for the $\mathrm{SM}$ and AT muscles (right and left) at $\mathrm{T}_{0}$ and $\mathrm{T}_{7}$ intervals were significantly different $(\mathrm{p}<0.05$; Table 1$)$. The results 


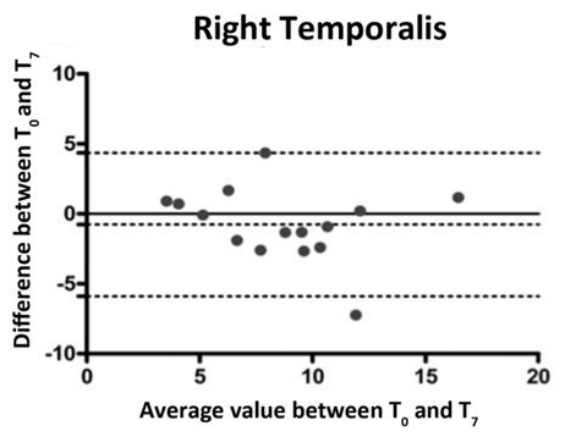

Right Masseter

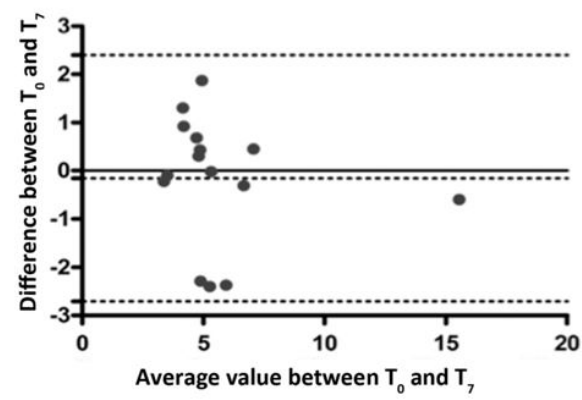

Left Temporalis

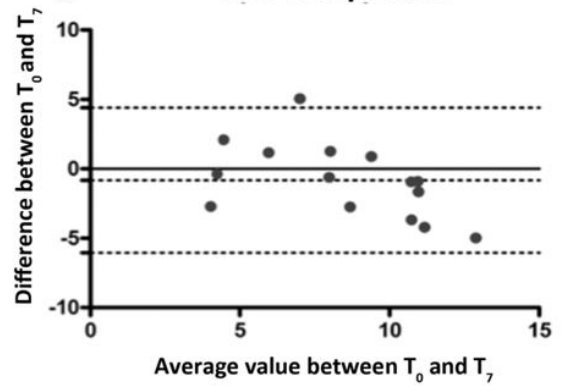

Left Masseter

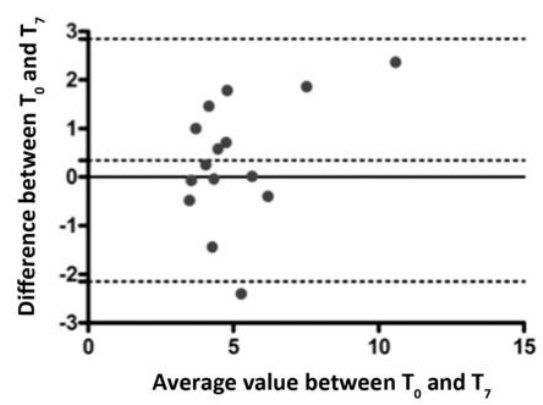

Figure 3. Bland-Altman plot of all four muscles evaluated at rest, with $95 \%$ upper and lower agreement limits, and average difference line. $\mathrm{T}_{0}$ - initial recording; $\mathrm{T}_{7}$ - recording after 7 days. Each dot on the plot represents one single volunteer. $\mathrm{X}$-axis represents an average value between $\mathrm{T}_{0}$ and $\mathrm{T}_{7}$. Values are expressed in $\mu \mathrm{V}$.

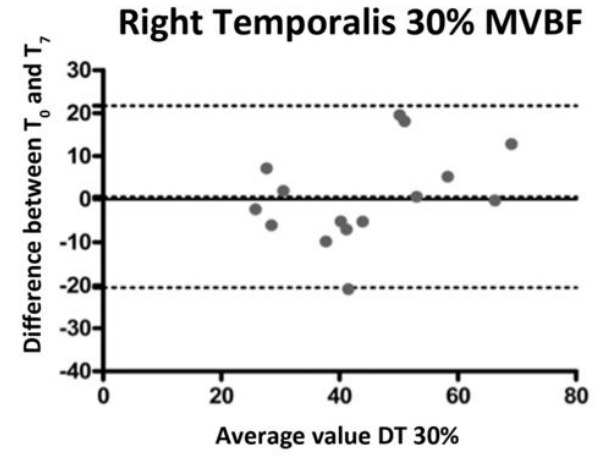

\section{Right Masseter 30\% MVBF}

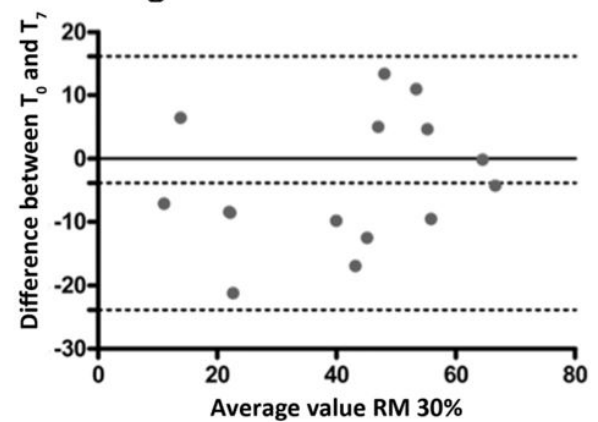

Left Temporalis 30\% MVBF

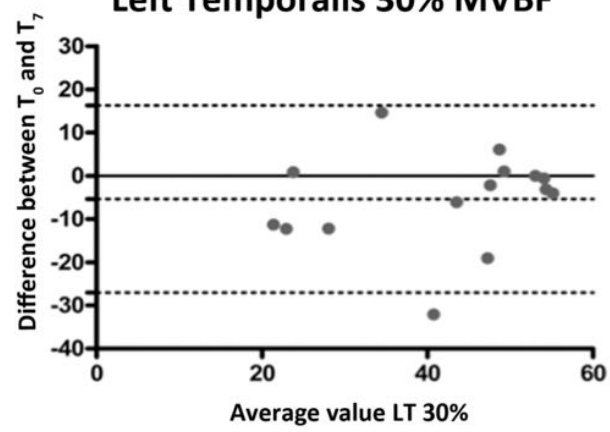

Left Masseter 30\% MVBF

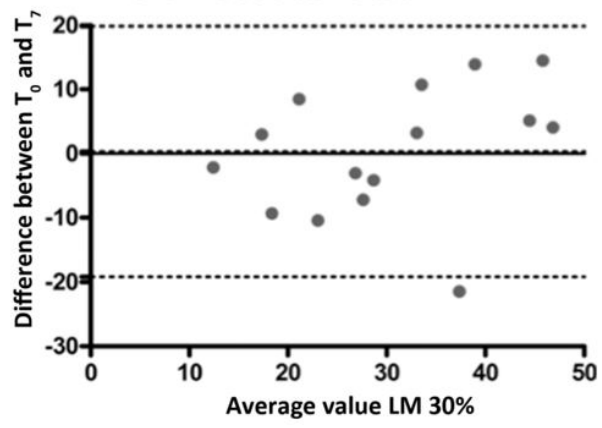

Figure 4. Bland-Altman plot of all four muscles evaluated at 30\% MVBF, with 95\% upper and lower agreement limits, and average difference line. $\mathrm{T}_{0}$ - initial recording; $\mathrm{T}_{7}$ - recording after 7 days. Each dot on the plot represents one single volunteer. $\mathrm{X}$-axis represents an average value between $\mathrm{T}_{0}$ and $\mathrm{T}_{7}$. Y-axis represents the difference between $\mathrm{T}_{0}$ and $\mathrm{T}_{7}$. Values expressed in $\mu \mathrm{V}$. 
Table 1. Intraclass correlation coefficient of RMS and MVBF values for the right and left AT and SM muscles.

\begin{tabular}{ccccc}
\hline Muscle & $\begin{array}{c}\text { Rest } \\
\text { (RMS } \\
\text { values) }\end{array}$ & $\begin{array}{c}\text { MVBF } \\
\text { (RMS } \\
\text { values) }\end{array}$ & $\begin{array}{c}\mathbf{3 0 \%} \\
\text { MVBF } \\
\text { (RMS } \\
\text { values) }\end{array}$ & $\begin{array}{c}\text { MVBF } \\
\text { (kgf) }\end{array}$ \\
\hline Right AT & 0.75 & 0.84 & 0.73 & \\
Left AT & 0.70 & 0.77 & 0.64 & 0.83 \\
Right SM & 0.91 & 0.92 & 0.91 & \\
Left SM & 0.82 & 0.86 & 0.65 & \\
\hline
\end{tabular}

Note: Values found at $\mathrm{T}_{0}$ (initial recording) and $\mathrm{T}_{7}$ (recording after 7 days) were compared by means the paired t-test. All results presented P-value $<0.05$. Results below 0.6 are considered of poor reproducibility; between 0.6 and 0.8 , of satisfactory reproducibility, and above 0.8 , of excellent reproducibility (Chan et al., 2008).

showed satisfactory to excellent reproducibility of RMS values at rest, $\mathrm{MVBF}$ and $30 \% \mathrm{MVBF}$, as well as for MVBF in kgf.

\section{Discussion}

The sEMG signal is variable by nature, even within few seconds between recordings (Donaldson and Donaldson, 1990; Hermens et al., 2000; Merletti and Parker, 2004). Therefore, the similarity of values when two different sEMG signal acquisitions occur at different instants of time are compared in the same individual should not be expected. The results found in this study depict an even sEMG data distribution that kept within the $95 \%$ limit of agreement from the statistical method employed. ICCs results showed satisfactory reproducibility (Table 1), supporting the hypothesis that the present protocols for electrodes positioning can be a feasible alternative for future studies. Our proposal was intended to overcome some limitations that hamper the optimal placement of electrodes over SM and AT muscles. Even though, to our knowledge, no previous study seemed to investigate the reproducibility of the SEMG signal from SM and AT muscles from standard surface electrodes, it should be clarified that this study was conducted from the recommendations reported by Castroflorio et al. (2005; 2006; 2008).

Among the methods of surface electrodes positioning previously described in the literature (Arat et al., 2008; Botelho et al., 2009; Ioi et al., 2006; Liu et al., 1999; Pedroni et al., 2004; Sabashi et al., 2009), some do not consider anatomical landmarks, or do not present any criteria to ensure reproducibility for repeated evaluations, which are usually based on the muscle belly, the midpoint of a muscle or along the muscle fibers direction, as routinely determined by palpation or visual observation. This kind of methodological approach emphasizes the importance of surface electrodes positioning over areas of greater muscle volume, from which the sEMG signal can be recorded from the larger cross-sectional area.
However, many studies do not usually provide details with regard to the positioning, IED, and direction of surface electrodes, nor even how to ensure reproducibility. On the other hand, anatomical landmarks can be used as references, ensuring greater reproducibility while positioning electrodes over facial muscles. Among these studies, some used reference landmarks that were not directly related to the anatomy of muscles of mastication, such as the labial commissure, tragus and exocanthion points (Alarcón et al., 2009; Bodéré et al., 2005).

The different tissues between the electrodes-muscle interface present anisotropic characteristics, therefore it is desirable that electrodes are placed at the same direction as muscle fibers. This will allow a pair of electrodes to pick up a spread of action potentials from the same bundle of muscle fibers, and thus, of corresponding muscle volumes (Hermens et al., 2000). Masseter's line of action is more vertical in brachycephalic individuals, while in dolichocephalic subjects this line of action seems to present greater inclination with regard to the Frankfort Horizontal Plane. Muscles differ between subjects. Thus, any recommendation for surface electrodes positioning based on anatomical landmarks that are not closely related to the muscles of interest, or are not individualized, would not respect the precept that electrodes must be placed parallel to muscle fibers and over its largest volume. When muscles of mastication are palpated in pain diagnosis, clinicians usually develop excellent digital perception, managing to define clearly the limits of masseter and temporalis muscles. This clinical maneuver becomes easier when the patient has some degree of muscle hypertrophy or square face. However, more information in regard to anatomical landmarks is needed to enhance method reproducibility, the main objective of the authors in this study.

Surface electrodes, in a bipolar configuration, should ideally be placed between the innervation zone and the tendinous insertion, depending directly on the anatomy of the muscle to be evaluated (Castroflorio et al., 2005; 2006; 2008; Garcia and Vieira, 2011; Mesin et al., 2009). The methodological approach proposed in the present study aims to avoid the most tendinous portion of masseter, based on anatomical information. Castroflorio et al. (2005) showed that the innervation zones of masseter and temporalis are widely dispersed, hampering electrodes placement over the recommended optimal anatomical region. The wide distribution of innervation zones may result in a disruption of the SEMG signal, even when electrodes move minimal distances $(\sim 2 \mathrm{~mm})$ from the source of the most representative myoelectric activity mainly when very small electrodes are used, which is a limiting factor to obtaining reproducible results. Maximum attention was given to electrodes placement in the present study, in an attempt to reproduce the site as accurately as 
possible. However, while positioning traditional surface electrodes in bipolar configuration on a particular spot, it is not possible to guarantee they might not be displaced a few millimeters from the "optimal" location even though their diameter $(1 \mathrm{~cm})$ allowed covering the most prominent muscles bulk. During marking and palpation, the soft tissue may undergo slight displacement, in the order of a few millimeters, depending on the direction of finger pressure applied to the skin.

The use of palpation during muscle contraction (Arat et al., 2008), zygomatic arch (Andrade et al., 2009) and gonial angle have already been referred by other studies (Andrade et al., 2009; Garcia-Morales et al., 2003; Leung and Hägg, 2001), however, in less detail than the exposed in this manuscript. The scalp boundary limits the placement of surface electrodes over AT muscle, as reported in previous studies (Andrade et al., 2009).

Another important factor to be discussed in sEMG studies is the influence of IED, which must be always taken in account since it affects the spectral and temporal contents of the signal (Tank et al., 2009; Telles et al., 2008). Moreover, according to Castroflorio et al. (2006), increasing IED improves the reproducibility of sEMG data from SM and AT muscles. Nevertheless, increasing IED can lead to the summation of unwanted "crosstalk" signals from adjacent muscles (Hermens et al., 2000) to the signal of interest. The SENIAM protocol recommends an IED of $20 \mathrm{~mm}$ for most muscles (Hermens et al., 2000), but for smaller ones, this distance should be reduced. We were able to adopt the IED recommended by SENIAM although the surface electrodes used in the presented study had to be partially cut out to be suitably placed over both muscles as can be seen in Figure 2B.

The results of this study showed satisfactory reproducibility (Table 1), indicating that the established protocols are a suitable and alternative approach for electrodes placement in future researches concerning the myoelectric activity of the SM and AT muscles. Interestingly, the sEMG data seemed to present great reproducibility for the right side in contrast to left one for both muscles. We may assume that since the force transducer was positioned over the lower first molar on the right side, it could explain such differences for MVBF and 30\% MVBF results, but not the sEMG signals recorded at rest position. Although we did not adopt any inventory of lateral preference or dominance to ascertain chewing side preference, it could be suggested a brain hemisphere influence on regulating muscle force differently from each hemiface even though some authors (Martinez-Gomis et al., 2009) raise some doubts about this particular issue; however this study did not gather information in this respect. Comparing our results with those obtained by Castroflorio et al. (2005), good reproducibility was obtained with smaller
IEDs, despite the difference concerning the temporal parameters investigated: The RMS value was used in the present study, whereas Castroflorio et al. (2005) used the average rectified value.

We have applied the Bland-Altman method to compare sEMG signal recordings performed by the same operator, within a seven-day interval, and for the same volunteers. All possible variables were controlled, excepting the time interval between the two tests. Repeating the test in a different day could result in a different psychological state; furthermore, the volunteers were already familiar with the research procedure at $T_{7}$. Moreover, operator's memory might influence the sEMG signal acquisition in the case of the interval of time between the two data recording was shorter. We observed that the AT and SM muscles reached amplitudes of $\pm 5(10 \mu \mathrm{V}$ peak to peak $)$ and $3 \mu \mathrm{V}(6 \mu \mathrm{V}$ peak to peak), respectively, during the rest condition. These results suggest that we were able to achieve sEMG signal with a very high $\mathrm{S} / \mathrm{N}$ ratio during the data acquisition. Despite the advantages of using the Bland-Altman method, no previous studies were found to use this analysis for assessing sEMG agreement for both muscles. It would be interesting to conduct additional investigations, testing several IEDs, and other types of electrodes, adapted to the protocols presented in this study, in order to check the reproducibility of sEMG.

The proposed protocols for surface electrodes placement on the SM and AT muscles have shown to be suitable, reproducible and of good accuracy. It is suggested that these methods can positively contribute to myoelectric activity monitoring of the muscles investigated in the present study.

\section{Acknowledgements}

To Carlos Chagas Filho Research Foundation of Rio de Janeiro State (FAPERJ) for supporting registered projects E-26/110987/2008 and E-26/110 543/2014, and the Undergraduate Anatomy Program/Biomedical Sciences Institute at the Federal University of Rio de Janeiro, for sharing the skull images.

\section{References}

Alarcón JA, Martín C, Palma JC, Menéndez-Núñez M. Activity of jaw muscles in unilateral cross-bite without mandibular shift. Arch Oral Biol. 2009; 54(2):108-14. PMid:19019348. http:// dx.doi.org/10.1016/j.archoralbio.2008.10.001.

Andrade AS, Gavião MBD, Derossi M, Gameiro GH. Electromyographic activity and thickness of masticatory muscles in children with unilateral posterior crossbite. Clin Anat. 2009; 22(2):200-6. PMid:19031391. http://dx.doi.org/10.1002/ca.20726.

Arat FE, Arat ZM, Acar M, Beyazova M, Tompson B. Muscular and condylar response to rapid maxillary expansion. Part 1: Electromyographic study of anterior temporal and superficial 
masseter muscles. Am J Orthod Dentofacial Orthop. 2008; 133(6):815-22. PMid:18538244. http://dx.doi.org/10.1016/j. ajodo.2006.07.028.

Bodéré C, Téa SH, Giroux-Metges MA, Woda A. Activity of masticatory muscles in subjects with different orofacial conditions. Pain. 2005; 116(1-2):33-41. PMid:15927390. http:// dx.doi.org/10.1016/j.pain.2005.03.011.

Botelho AL, Melchior MO, Silva AMBR, Silva MAMR. Electromyographic evaluation of neuromuscular coordination of subject after orthodontic intervention. Cranio. 2009; 27(3):1528. PMid:19697642. http://dx.doi.org/10.1179/crn.2009.023.

Castroflorio T, Bracco P, Farina D. Surface electromyography in the assessment of jaw levator muscles. J Oral Rehabil. 2008; 35(8):638-45. PMid:18466277. http://dx.doi.org/10.1111/j.13652842.2008.01864.x

Castroflorio T, Farina D, Bottin C, Debernardi P, Bracco P, Merletti R, Anastasi G, Bramanti P. Non-invasive assessment of motor unit anatomy in jaw-elevator muscles. J Oral Rehabil. 2005; 32(10):708-13. PMid:16159347. http://dx.doi.org/10.1111/j.13652842.2005.01490.x.

Castroflorio T, Icardi K, Becchino B, Merlo E, Debernardi C, Bracco P, Farina D. Reproducibility of surface EMG variables in isometric sub-maximal contractions of jaw elevator muscles. J Electromyogr Kinesiol. 2006; 16(5):498-505. PMid:16291500. http://dx.doi.org/10.1016/j.jelekin.2005.08.007.

Chan HJ, Woods M, Stellac D. Mandibular muscle morphology in children with different vertical facial patterns: a 3-dimensional computed tomography study. Am J Orthod Dentofacial Orthop. 2008; 133(1):10.e1-.e3. PMID:18174063.

Donaldson S, Donaldson M. Multi-channel EMG assessment and treatment techniques. In: Cram JR, editor. Clinical EMG for surface recordings. 2nd ed. Nevada City: Clinical Resources; 1990.

Garcia MAC, Vieira TMM. Surface electromyography: why, when and how to use it. Rev Andal Med Deporte. 2011; 4:17-28.

Garcia-Morales P, Buschang PH, Throckmorton GS, English JD. Maximum bite force, muscle efficiency and mechanical advantage in children with vertical growth patterns. Eur J Orthod. 2003; 25(3):265-72. PMid:12831216. http://dx.doi. org/10.1093/ejo/25.3.265.

Gonzalez Y, Iwasaki LR, McCall WD Jr, Ohrbach R, Lozier E, Nickel JC. Reliability of EMG activity versus bite-force from human masticatory muscles. Eur J Oral Sci. 2011; 119:219-24. PMid:21564316. http://dx.doi.org/10.1111/j.1600-0722.2011.00823.x.

Hackney J, Bade D, Clawson A. Relationship between forward head posture and diagnosed internal derangement of the temporomandibular joint. J Orofac Pain. 1993; 7(4):386-90. PMid:8118442.

Hermens HJ, Freriks B, Disselhorst-Klug C, Rau G. Development of recommendations for SEMG sensors and sensor placement procedures. J Electromyogr Kinesiol. 2000; 10(5):361-74. PMid:11018445. http://dx.doi.org/10.1016/S1050-6411(00)00027-4.

Ioi H, Kawakatsu M, Nakata S, Nakasima A, Counts AL. Mechanomyogram and electromyogram analyses for investigating human masseter muscle fatigue. Orthod Waves. 2006; 65(1):1520. http://dx.doi.org/10.1016/j.odw.2005.12.002.
Klasser GD, Okeson JP. The clinical usefulness of surface electromyography in the diagnosis and treatment of temporomandibular disorders. JAm Dent Assoc. 2006; 137(6):763-71. PMid:16803805. http://dx.doi.org/10.14219/jada.archive.2006.0288.

Leung DK, Hägg U. An electromyographic investigation of the first six months of progressive mandibular advancement of the Herbst appliance in adolescents. Angle Orthod. 2001; 71(3):177-84. PMid:11407769.

Liu ZJ, Yamagata K, Kasahara Y, Ito G. Electromyographic examination of jaw muscles in relation to symptoms and occlusion of patients with temporomandibular joint disorders. J Oral Rehabil. 1999; 26(1):33-47. PMid:10080323. http://dx.doi. org/10.1046/j.1365-2842.1999.00356.x.

Martinez-Gomis J, Lujan-Climent M, Palau S, Salsench J, Peraire M. Relationship between chewing side preference and handedness and lateral asymmetry of peripheral factors. Arch Oral Biol. 2009; 54(2):101-7. PMid:18947820. http://dx.doi. org/10.1016/j.archoralbio.2008.09.006.

Merletti R, Parker PA. Electromyography - physiology, engineering and noninvasive applications. New Jersey: John Wiley \& Sons; 2004.

Mesin L, Merletti R, Rainoldi A. Surface EMG: The issue of electrode location. J Electromyogr Kinesiol. 2009; 19(5):719-26. PMid:18829347. http://dx.doi.org/10.1016/j.jelekin.2008.07.006.

Pedroni CR, Borini CB, Berzin F. Electromyographic examination in temporomandibular disorders - evaluation protocol. Braz $\mathrm{J}$ Oral Sci. 2004; 3:526-9.

Sabashi K, Saitoh I, Hayasaki H, Iwase Y, Kondo S, Inada E, Takemoto Y, Yamada C, Yamasaki Y. A cross-sectional study of developing resting masseter activity in different angle classifications in adolescence. Cranio. 2009; 27(1):39-45. PMid:19241798. http://dx.doi.org/10.1179/crn.2009.007.

Suvinen TI, Kemppainen P. Review of clinical EMG studies related to muscle and occlusal factors in healthy and TMD subjects. J Oral Rehabil. 2007; 34(9):631-44. PMid:17716262. http://dx.doi.org/10.1111/j.1365-2842.2007.01769.x.

Suvinen TI, Malmberg J, Forster C, Kemppainen P. Postural and dynamic masseter and anterior temporalis muscle repeatability in serial assessments. J Oral Rehabil. 2009; 36(11):814-20. PMid:19744168. http://dx.doi.org/10.1111/j.1365-2842.2009.01999.x.

Tank FF, Silva GT, Oliveira CG, Garcia MAC. Influência da distância intereletrodos e da cadência de movimento no domínio da frequência do sinal de EMG de superfície. Rev Bras Med Esporte. 2009; 15(4):272-6. http://dx.doi.org/10.1590/S151786922009000500008 .

Telles G, Tank FF, Alves RB, Barbieri LK, Oliveira CG, Garcia MAC. Influência da distância intereletrodos no domínio do tempo do sinal de EMG de superfície em contrações isotônicas do músculo bíceps braquial. Arq Mov. 2008; 4:16-33.

Tosato JP, Caria PHF. Electromyographic activity assessment of individuals with and without temporomandibular disorders symptoms. J Appl Oral Sci. 2007; 15(2):152-5. PMid:19089121. http://dx.doi.org/10.1590/S1678-77572007000200016. 